AROUEOLOGÍA Y SOCIEDAD

№ 28, 2014: 199-216

ISSN: 0254-8062

RECIBIDO: MARZO DE 2014

ACEPTADO: SETIEMBRE DE 2014

\title{
¿PUCULLOS? EN LAS CUENCAS DE LOS RÍOS WARPA, URUBAMBAY MANTARO, ENTRE AYACUCHOY HUANCAVELICA, PERÚ
}

\author{
Julio ERNEsto VALDEz CÁrdenas \\ UNIVERSIDAD NACIONAL SAN CRISTÓBAL DE HUAMANGA \\ ernestovaldezcardenas@hotmail.com
}

\section{RESUMEN}

En este artículo se presenta una información novedosa de la existencia de estructuras arquitectónicas construidas con piedras y barro que forman cámaras funerarias que están estratégicamente construidas en peñascos y a la sombra de grandes bloques de piedras o rocas que permitan su sequedad. Estos tipos de cámaras se vienen ubicando en las inmediaciones de la cuenca del rio Warpa y en su confluencia con el río Mantaro, en territorios del departamento de Ayacucho y Huancavelica, en el Perú.

PalabRas Clave: Pucullos, río Warpa, río Mantaro.

\begin{abstract}
Innovative information of the existence of architectonic structures forged with stones and clay those funerary cameras that are strategically constructed in large rocks form shows up in this article and to the shade of big stones block or rocks that enable your dryness. These types of cameras come themselves locating at the surroundings of the basin of the river Warpa and in your confluence with the river Mantaro, at territories of Ayacucho's and Huancavelica's department, in the Peru.
\end{abstract}

KEYWORDS: Pucullos, Warpa river, Mantaro river.

\section{INTRODUCCIÓN}

Existen antecedentes en la historia andina de cómo los hombres, desde tiempos muy tempranos, trataron de proteger y preservar el cuerpo de sus muertos. Las primeras evidencias las encontramos en las cuevas de Telarmachay y Lauricocha, donde los entierros presentan el cuidado y el trato que recibieron. Todo esto, hasta el advenimiento de la sociedad Inka, ha logrado evolucionar y diversificarse, de tal manera que, como menciona Bartolomé de las Casas (1892), allá para los tiempos de la conquista, tenían tumbas diferentes y diferentes modos de entierro. En ese sentido, confirmando lo antes mencionado, las recientes investigaciones arqueológicas vienen registrando formas diversas de tratamiento a los muertos que se practicaron durante los periodos prehispánicos, tal como se presenta en este artículo, donde se detalla las formas de patrones de enterramiento que se desarrolló durante el Periodo del Horizonte Medio en la parte norte de la cuenca del río Warpa y de las inmediaciones donde este río confluye con el río Mantaro, aquí en las fronteras entre los departamentos de Ayacucho y Huancavelica. 


\section{MEDIO GEOGRÁFICO}

Nuestro estudio abarca el espacio geográfico que están en las inmediaciones donde el río Warpa confluye con el río Mantaro, donde está las prolongaciones del cerro de Razuwillka, del cerro Omaconga, o en los fuertes pendiente que ha creado el cañón de Huatuscalla por donde transcurre el río Mantaro entre los límites de los departamentos de Huancavelica y Ayacucho; en terrenos altos y accidentados peñascos de difícil acceso, donde se encuentran abrigos rocosos, se ha logrado ubicar estructuras arquitectónicas laboriosamente construidas y que corresponden a cámaras funerarias.

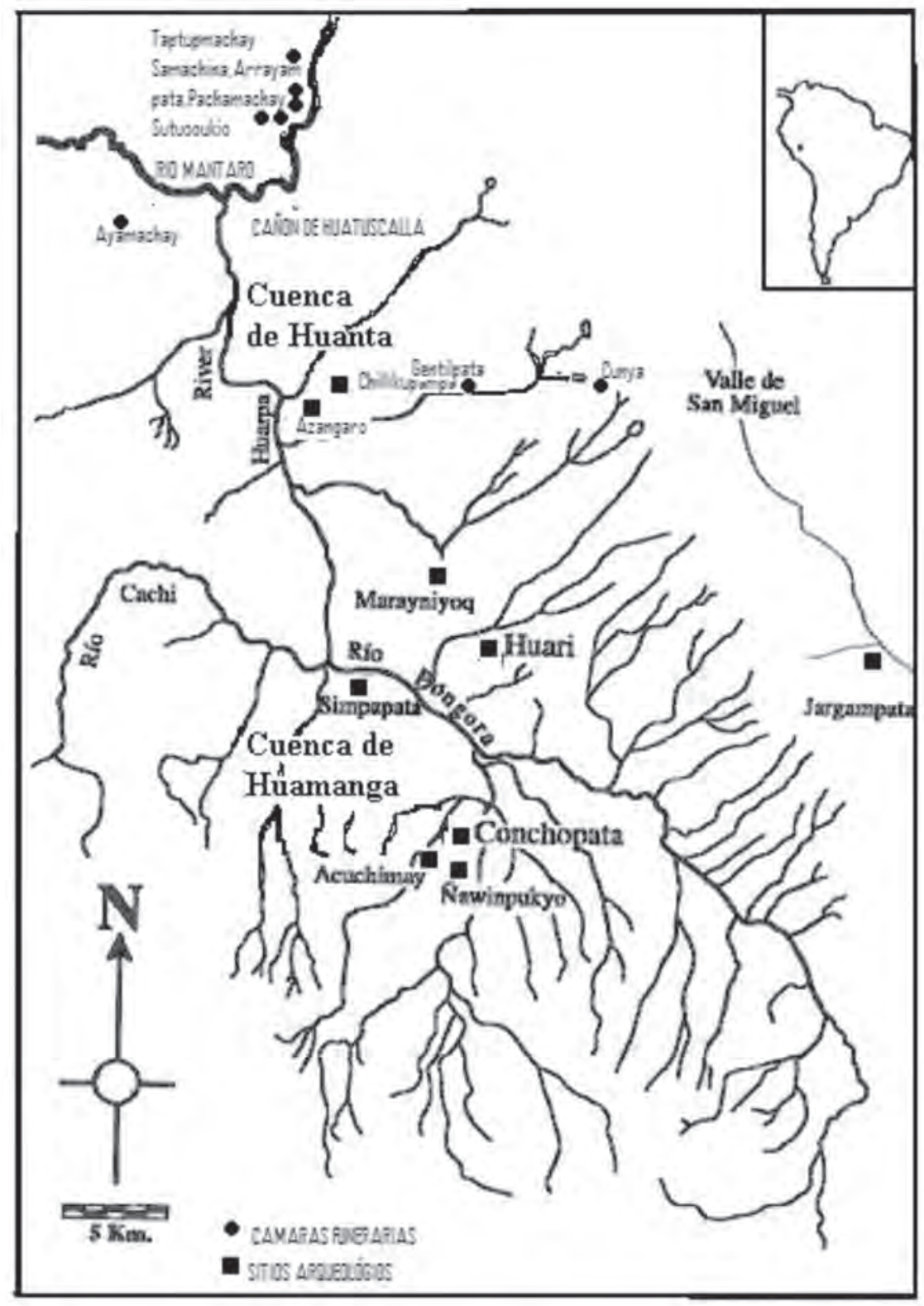

Figura 1. Ubicación de las cámaras funerarias. 


\section{ESTUDIOS PREVIOS}

El interés por entender de cómo las habitantes durante el Horizonte Medio, trataron y cuidaron el cuerpo de sus muertos y cuáles fueron las medidas que tomaron para preservar, es también objeto de estudio de la arqueología. En ese sentido, en lo que corresponde a esta zona, existen trabajos pioneros, como los realizados por William Isbell para el caso de Conchopata, o el sitio arqueológico Wari ubicado en Ayacucho, donde se considera que los cuerpos de los muertos fueron tratados de distintas formas, y en la que identifica ciertas tipologías, en las que concluye presentando varios tipos de prácticas funerarias: entierros individuales cavado en suelo, entierros múltiples en cista, entierro individual en cista, entierros en cavidad rocosa, entierros en construcciones mortuorias, entierros en paredes y entierros grupales de victimas de sacrificio (Isbell 2000: 9-68). Tenemos las investigaciones llevadas a cabo por Lidio y Ernesto Valdez en Seqllas, en el valle de Huanta, en la que se expuso una estructura subterránea amplia para entierros múltiples que presenta un acceso orientado hacia el este (Valdez, Bettcher y Valdez 2000) Los trabajos de Ernesto Valdez para el caso de sitio arqueológico de Pusuquypata-Chillikupampa, provincia de Huanta, en la que encontró seis formas distintas de entierro, tales como: entierros individual cavados en el suelo, entierro individual en cistas, entierros en hornacinas o en paredes, entierros en cistas en forma de bota, entierros en cámaras funerarias, entierros grupales de cuerpos extendidos o sacrificados y entierros con cuerpos en posición fetal ubicado en las esquinas de los recintos (Valdez 2009; Valdez, Valdez y Bettcher 2005). Para el caso de Marayniyoq, sitio arqueológico del periodo Wari, ubicado al norte del sitio Wari, se logró exponer una estructura que tenía la forma rectangular, con paredes de piedra y barro y un techo de piedras trabajadas (Valdez, Valdez y Bettcher 2005: 179).

Aparte de estas formas, creemos que hubo otras formas de patrones de enterramiento, debido que se ha ubicado en estas zonas, tumbas no directamente asociados a un sitio arqueológico específico, pero que si están asociados a cerámica del Horizonte Medio, a la que los llamaremos Cámaras Funerarias o Pucullos, que están dentro o debajo de peñascos o cuevas. Estos desde luego difieren completamente de las tumbas encontradas en Conchopata, Seqllas, Chillikupampa y Marayniyoq, y que hasta la fecha se ha logrado ubicar en muchos lugares que están dentro del área de estudio inicialmente presentado. De tal manera que, como hace referencia Guamán Poma de Ayala, cuando se ocupa de los indios Aucaruna, a los que considera como los antecesores inmediatos de la sociedad inka, donde menciona que estos: «enterraban sus muertos con muchos honores en bóvedas especiales llamadas Pucullo, de las cuales muchas de ellas se edificaban en forma especial para enterrar a los señores principales, siendo blanqueados y pintados, se hacían los entierros sin ceremonias ni actos de idolatría.» (Bustios 1956:51). Igualmente, Enrique Gonzales menciona que «Las cuevas y abrigos rocosos constituyeron lugares que eran utilizados con fines de enterramiento, para lo cual la parte externa o entrada era cerrada mediante un muro de protección, aislado la parte interna donde se depositaba el cadáver, enterrado bajo el nivel del piso ya sea en tumbas individuales o múltiples. El cadáver se encontraba envuelto en tela de lana, amarrado con soguilla y tenía como ofrenda piezas de cerámica de distintos tamaños» (1992).

Evidencias con estas características serán presentadas en este artículo, con el objeto de llamar la atención sobre la presencia de nuevas formas de patrones de enterramiento en estas zonas de la cuenca del río Warpa, y estas son las que siguen:

I. Para empezar, tenemos, el caso de las Tumbas de Gentilpata, que se encuentran ubicadas dentro de las accidentadas topografías de Condorqaqa, que queda encima de la comunidad de Chula, en las alturas de la localidad de Huanta, provincia de Huanta, Ayacucho. Aquí, debajo de una negruzca y accidentada roca que se encuentra a la margen derecha de la quebrada donde discurre el río Huanta, dentro de los terrenos de la familia Romaní, en plena zona donde la región Suni da paso a la región Puna, a 3641 msnm, se encuentran dichas estructuras arquitectónicas. 

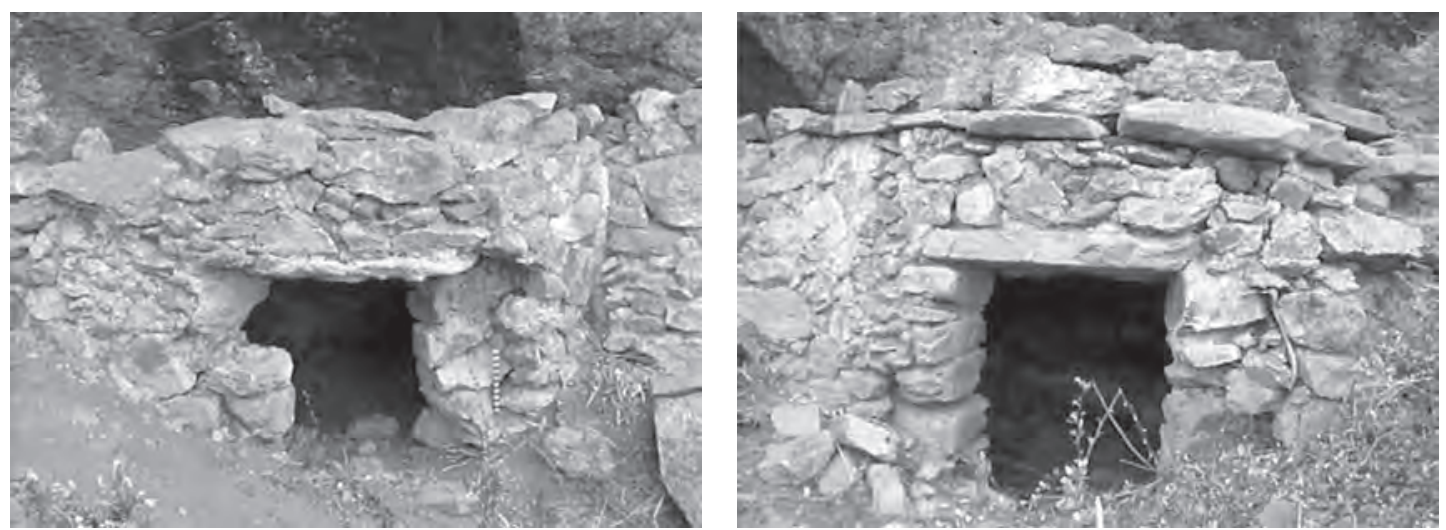

Figura 2. Véase las cámaras funeraria de Gentilpata, Comunidad de Chula, Huanta.

Los Pucullos de Gentilpata constan de cuatro ambientes. Están construidas con piedras y mortero de barro mezclado con ichu. Son pequeños ambientes que cuyos lados laterales y frontales, están delimitados con muros, mientras el lado posterior está adosado a la roca que forma parte del peñasco. Sus techos están construidos con grandes y aplanadas lajas de piedra, que adecuadamente puestas protegen y cubren la parte superior de las cámaras. Todas las cámaras funerarias o Pucullos orientan sus puertas hacia el sur.

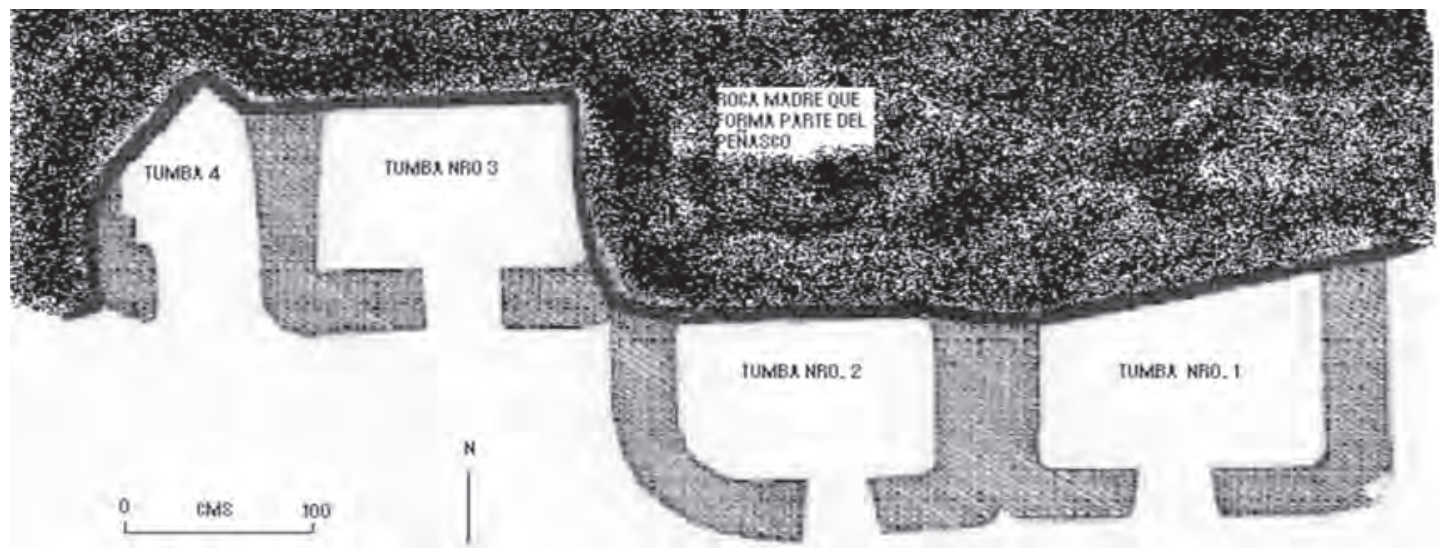

Figura 3. Véase dibujo de planta de las cámaras funeraria de Gentilpata, Comunidad de Chula, Huanta.

La primera cámara funeraria que se encuentra hacia el este y es la más grande, presenta un área de acceso (vano) cuyo umbral está conformado por una piedra más larga. Este acceso tiene $42 \mathrm{~cm}$ de ancho por $70 \mathrm{~cm}$ de altura, y un muro de $30 \mathrm{~cm}$ de ancho. La altura de la cámara llega hasta los 1,53 $\mathrm{m}$ a 1,10 m de altura, es curioso ver cómo sobresale las lascas del techo hacia el exterior, en unos $8 \mathrm{~cm}$, con la finalidad de proteger la pared exterior de la tumbas, a razón de que esta estaba estucada con una fina y gruesa capa de arcilla. En lo que respecta a su techo, está cubierta por lajas de piedra. En lo que concierne a su espacio interior, es irregular, tiene un largo de 1,78 $\mathrm{m}$ y un ancho irregular de $1 \mathrm{~m}$ en el oeste y $1,30 \mathrm{~m}$ en el este.

La segunda cámara funeraria se ubica al oeste de la primera. Presenta un vano con las mismas características que la anterior, de $40 \mathrm{~cm}$ de ancho por $60 \mathrm{~cm}$ de altura. Su muro presenta $30 \mathrm{~cm}$ de ancho. Esta tumba tiene 1,15 $\mathrm{m}$ de altura, y un espacio interior irregular de 1,60 m de largo por $1 \mathrm{~m}$ de ancho. 


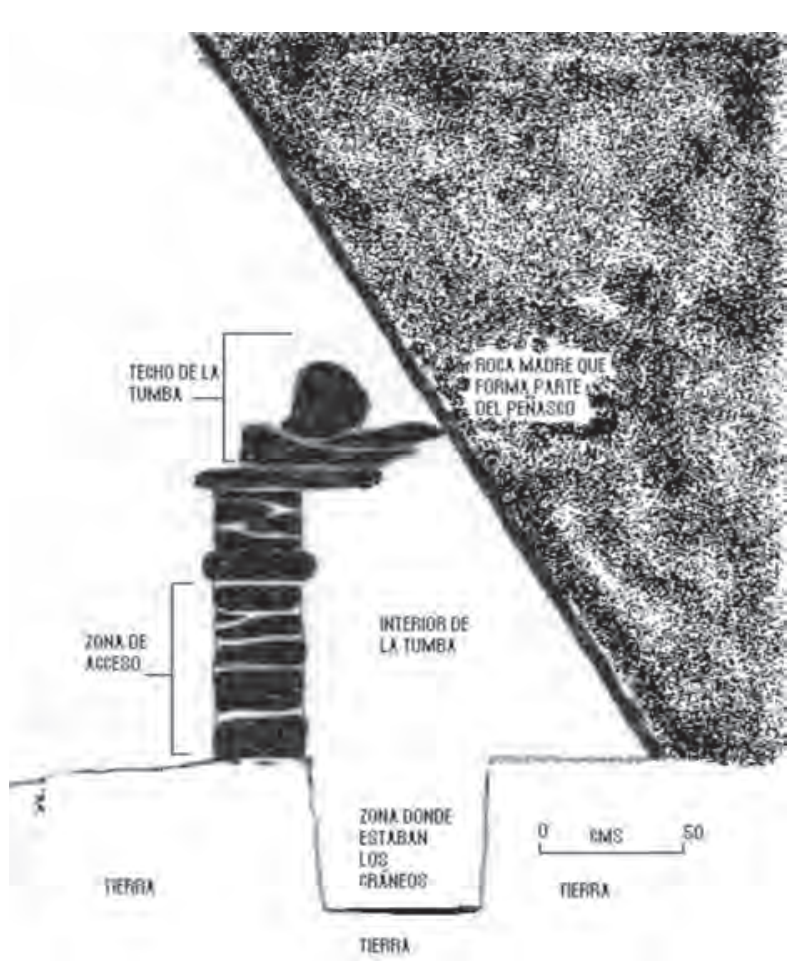

Figura 4. Véase dibujo de corte de una de las cámaras funerarias de Gentilpata.

La tercera cámara funeraria que queda hacia el oeste de la segunda, lamentablemente estaba destruida razón por la que nos es imposible saber su verdadera dimensión, y nos limitaremos sólo a mencionar alguna medidas. Su vano presentaba $47 \mathrm{~cm}$ de ancho, su muro era de unos $40 \mathrm{~cm}$ de ancho, su espacio interior es irregular, con 1,60 m de largo y 1,10 m de ancho, aproximadamente.

La cuarta cámara funeraria se encuentra hacia el oeste. Es una pequeña cámara que se encuentra en un sector más accidentado y reducido, también estaba completamente destruido, razón por la que nos es imposible definir su verdadera dimensión.

Lamentablemente, como comúnmente suele ocurrir, estas tumbas estaban profanadas, durante nuestra visita (noviembre de 2003) encontramos que los restos óseos humanos estaban expuestos en los exteriores de la tumba. Todas las cámaras estaban abiertas, y no había huesos visibles en el interior. Solo dos de ellas guardaban su originalidad en su estructura, mientras que los demás están destruidos. Previo registro exterior e interior, se pudo recuperar lo siguiente:

En la primera cámara, durante la limpieza interior, se ha llegado a encontrar excremento de zorros y de vizcacha, asociado a ramas y raíces de arbustos. En el interior de la cámara, en el sector suroeste, se encontró un hoyo que presentaba $60 \mathrm{~cm}$ de diámetro por $60 \mathrm{~cm}$ de profundidad, la misma que estaba rellenada. En el interior estaban puestos, en forma desordenado, cuatro cráneos. Pareciera que los profanadores, una vez cometido su objetivo, por ciertas consideraciones, depositaron los cráneos, y dejando desparramados los demás restos óseos fuera de la tumba. Los cuatro cráneos hallados, presentan deformación craneana. Esta práctica entre los antiguos peruanos, tiene profundas raigambres culturales, así a la llegada de los españoles esta fue una práctica común entre los Incas (Weiss 1962) Durante la sociedad Wari, esta práctica no fue extraña, así en los resultados de los trabajos de excavación de Chillikupampa se ha registrado cráneos deformados, Desde luego estas deformaciones presentar haber sido practicadas mediante las fajas deformadoras (llauto). En la opinión de Weiss (1962), la deformación por llauto fue predominantemente una práctica serrana, posiblemente como una distinción social dentro de la sociedad Wari, o una distinción étnica grupal en el mundo andino.

Junto a estos cráneos se encontró un mortero y una pequeña piedra muy redonda, que sería el contenido de una boleadora (arma defensiva construida en cuero).

La segunda cámara funeraria, similar que la anterior, estaba profanada. Durante la limpieza se llegó a encontrar una cabeza de fémur trabajado, y asociado a ello se recuperó un fragmento de cráneo, que presenta ciertas incisiones en su superficie, con claras muestras decorativas.

Respecto a la tercera cámara funeraria, esta estaba destruida, apenas quedaban los cimientos, y previa una limpieza se llegó a recuperar tres agujas de hueso que pueden ser partes de un collar: la primera mide $15 \mathrm{~cm}$ de largo; la segunda, $13 \mathrm{~cm}$ y la tercera $8,5 \mathrm{~cm}$. Junto con estos se encontró tres 


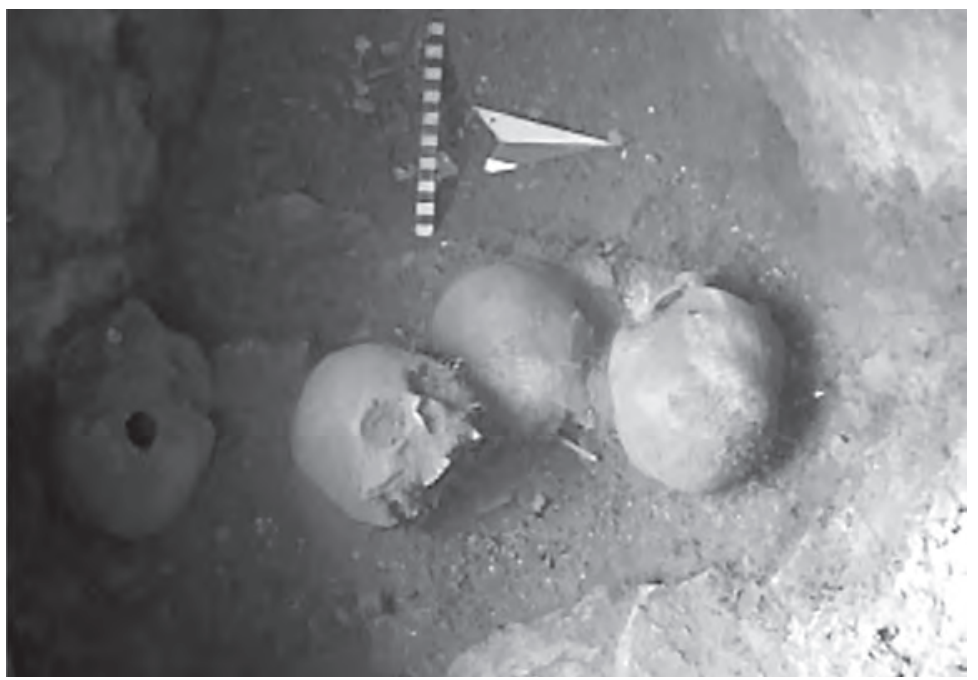

Figura 5. Véase la disposición de los cráneos dentro de una de las cámaras funerarias de Gentilpata.

pequeños huesos que parecen corresponder a algún ave o roedor mayor trabajado para un collar. Igualmente se halló un punzón de hueso que mide 7,5 cm de largo. En esta estructura, asociado a estos objetos, se recuperó un pequeño fragmento de mate (Lagenaria sp.), la misma que presenta incisiones intencionalmente hechas en su superficie externa, a lo que comúnmente se le llama el burilado (mate burilado). Similar a esto se encontró en la tumba de Ayamachay, en Marcas, como también en las tumbas de Ayauchco en Julcamarca, dentro del departamento de Huancavelica (Valdez 2003). Desde luego este formó parte del aguar funerario, ya que el mate es una planta que fácilmente se puede conseguir a razón de que se siembra en la ceja de la selva ayacuchana, y más aún en la misma hondonada por donde pasa el río Mantaro (Ibid. 18). Junto a estos se recuperó restos óseos de cuy (Cavia porcellus) que según las investigaciones arqueológicas, al igual que los camélidos, fue parte de la dieta alimenticia durante el devenir histórico de la cultura andina, y fue domesticado entre los 5000 y 3700 años A.P. La presencia de restos óseos de este animal es frecuente en muchos sitios arqueológicos, tal como vienen demostrando muchos trabajos de investigación. La presencia de restos óseos del cuy en sociedades como la de Wari ya no es una novedad, lo que vale suponer que los restos de cuy encontrados en estas tumbas de Gentilpata, fue parte del ajuar funerario, tal como sostiene Rofes (2000: 2), el cuy aparte de ser útil para consumo como alimento, como herramienta de diagnóstico médico y agente adivinador, asociado a que tenga algunas propiedades curativas, fue también utilizado para ser sacrificado como «ofrenda». Y en esta ocasión formó parte del ajuar funerario que fue ofrendado a los muertos. Igualmente se halló dos pedazos de diferentes grosores de soguillas de fibra vegetal, que seguramente formó parte de la soguilla con la que fue atado el individuo. Seguramente el cadáver estuvo en posición fetal y envuelto con algunos mantos, tal similar a un fardo, razón por la que se llegó a encontrar un pequeñísimo fragmento de tela en dicha tumba.

II. En lo que respecta a la cueva de Ayamachay, ubicado en territorio huancavelicano muy cerca de la localidad de Marcas, debajo de una gran roca que se orienta hacia la quebrada del Mantaro, en una cueva cuya boca de entrada mide $9 \mathrm{~m}$ de ancho por $4 \mathrm{~m}$ de altura y $5 \mathrm{~m}$ de profundidad, en cuyo interior, se encuentra un espacio seco y protegido, donde se pudo observar la presencia de muros de piedra unidos con argamasa correspondientes a pequeñas estructuras arquitectónicas de planta circular, asociado a cierta cantidad de restos óseos humanos: fémures, costillas, pelvis, cráneos, etc. Entre estas, un fragmento de cráneo que se llegó a registrar presenta rasgos de haber sufrido deformación craneana, y está asociado a un fragmento de mate con incisiones o burila- 


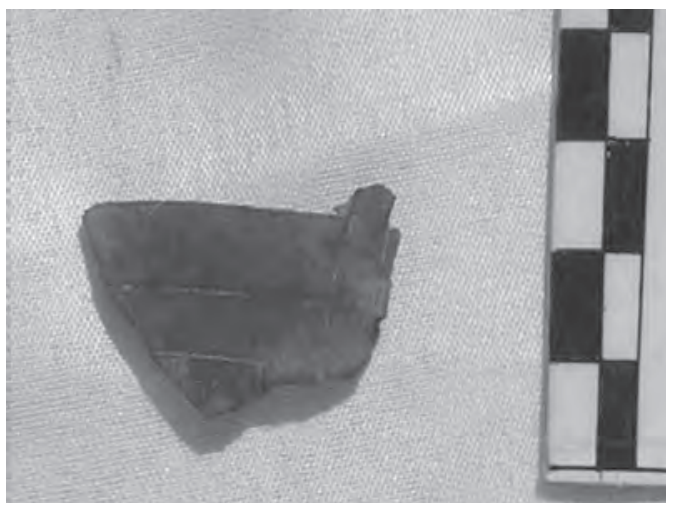

Figura 6. Véase Fragmento de mate (Lagenaria sp.) dentro de las cámaras funerarias de Gentilpata.

do (Valdez 2003: 16-17). Lo curioso en el interior de esta cueva, sobre una superficie irregular, es que en el piso aparece una estructura arquitectónica construida con piedras y barro de forma circular de 60 $\mathrm{cm}$ de diámetro, que actualmente está destruida. La presencia de esta sugiere pensar que fue una estructura funeraria, dentro de la que posiblemente estuvieron algunos o todos los individuos que ahora lamentablemente sus restos óseos están expuestos.

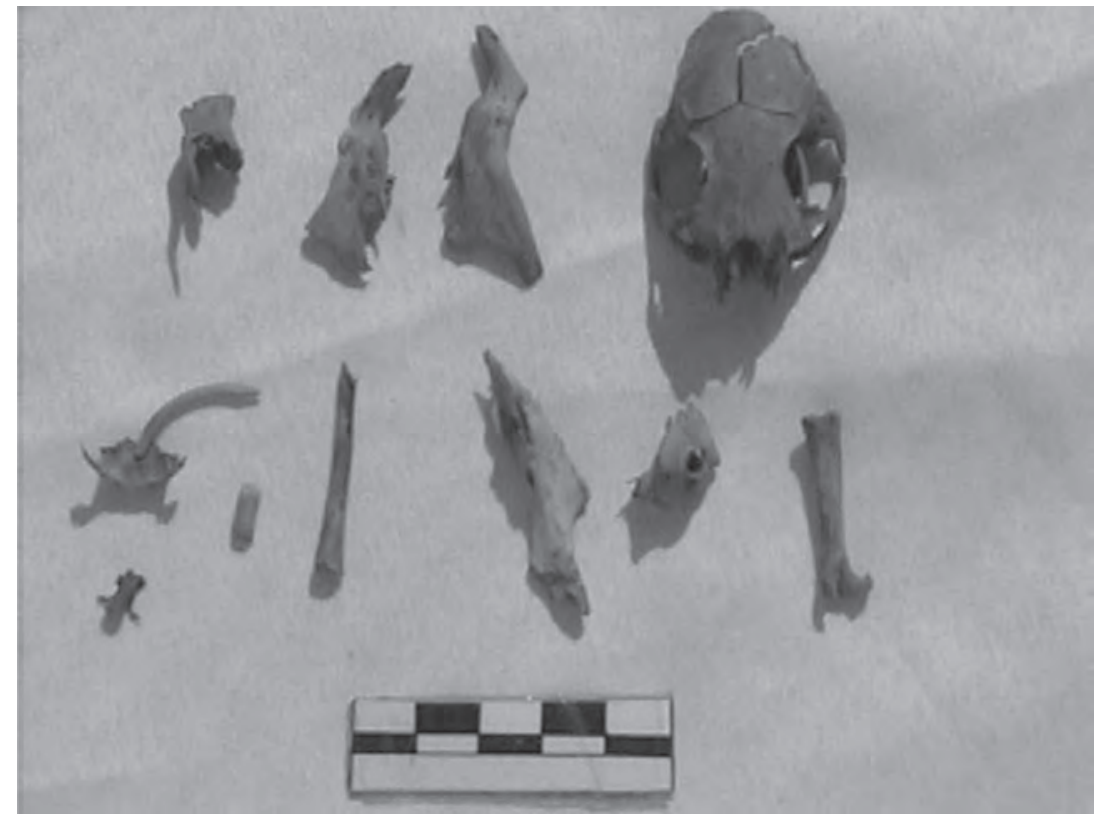

Figura 7. Véase restos de cuy (Cavia porcellus) encontrados en una de las cámaras funerarias de Gentilpata.

Tal evidencia confirma lo siguiente, que en aquellos tiempos no sólo bastaba depositar los fardos en las cuevas, sino que previamente dentro de la cueva se preparaba un edificación especial. Tal es el caso de Ayamachay, donde se elaboró una tumba de forma circular en el piso interior de la cueva, utilizando piedras con argamasa de barro, para depositar dentro de esta a los cuerpos.

Según los vecinos, el saqueo de estas tumbas se ha intensificado cada vez más desde las temporadas de los años 70 del siglo pasado, después de la reforma agraria, ya que desde entonces en sus inmediaciones se crearon campos de cultivo y áreas de pastoreo (Información personal, Bertha Ruiz 1998). Según Vicente Pinco (Información personal 1999) la cueva de Ayamachay antiguamente fue muy profunda, antes de ser saqueada se podía ver vasijas y algunos restos con sus respectivos mantos. Dice: «Mi padre cuando era joven encontró unas vasijas, las mismas que desaparecieron de su casa».

III. Similar información tenemos para el caso del cerro Coras, ubicado en Caja Espíritu, en la que se llegó a encontrar cráneos deformados y trepanados (Información personal de Oswaldo Reza: 1998). Igualmente se ha encontrado algunas estructuras similares, en condiciones disturbadas, en 
la cueva de Alalac Machay, en las alturas de la comunidad de Pumacocha, Acobamba. Similar estructura se puede observar en las alturas de Razuwillka, allá por la comunidad de Cunya, a pocos kilómetros de Uchuraccay, donde aparecen debajo de los peñascos estructuras de piedra y barro que son parte de cámaras funerarias, y que están destruidas, y en cuyo interior aun aparecen los restos óseos humanos.

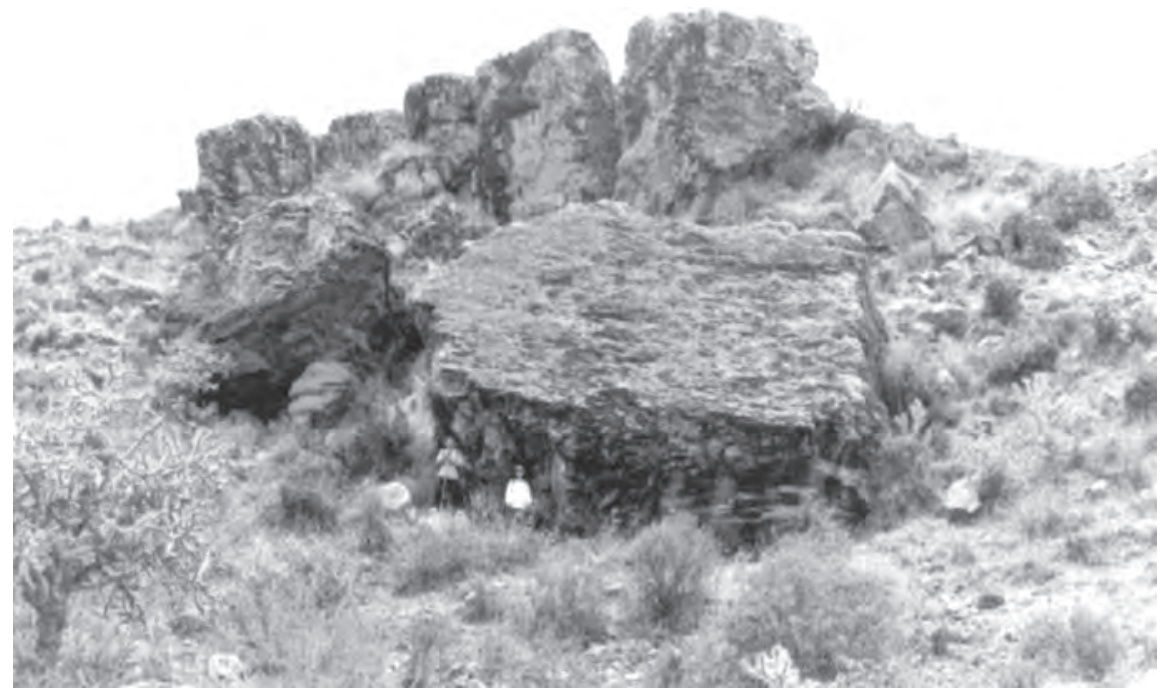

Figura 8. Véase el bloque de roca, debajo de la que se encuentra la cámara funeraria de Ayamachay.

IV. Cámaras funerarias con características similares se ha logrado registrar en las comunidades de Ccotccoy y Paccay en la provincia de Churcampa, del departamento de Huancavelica, en la zona fronteriza con el departamento de Ayacucho, justamente donde el río Mantaro después de recoger las aguas del río Warpa, abre una profunda quebrada de más de dos kilómetros de profundidad. Allí tenemos las cámaras funerarias de Taptumachay, ubicado en una pendiente que se desli-

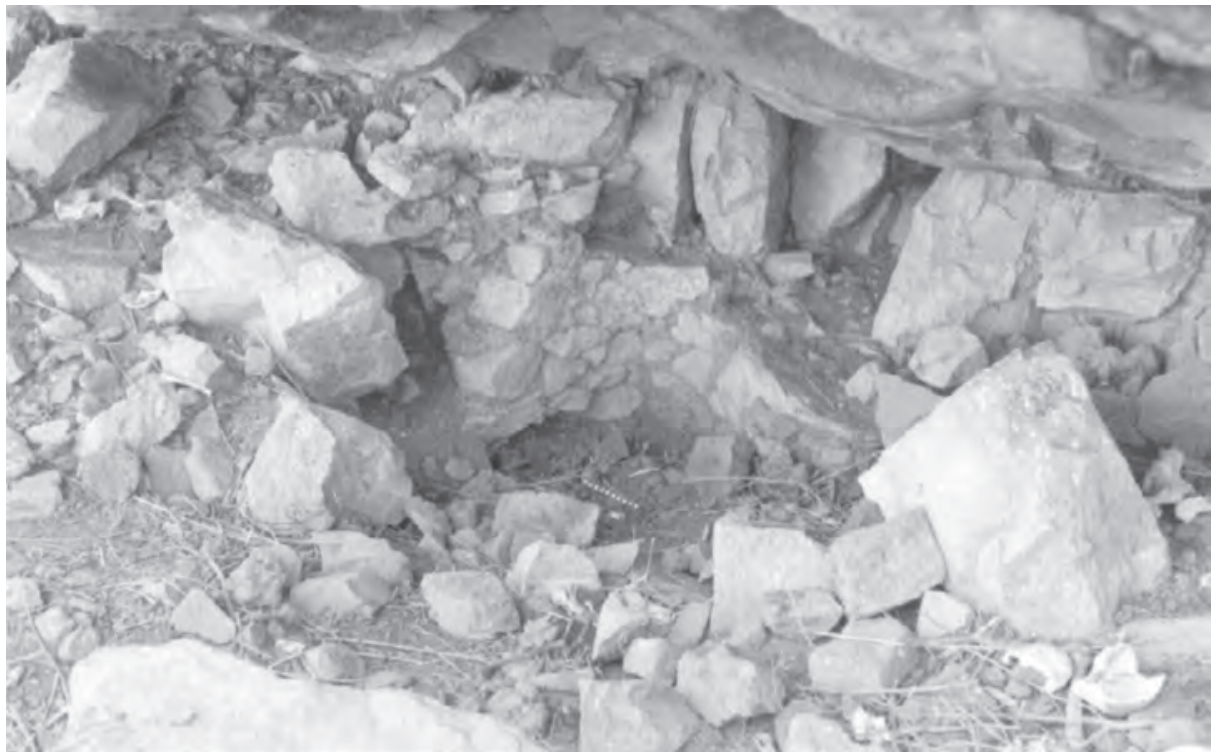

Figura 9. Véase la estructura arquitectónica destruida debajo dentro de la cueva. 
za hacia el centro poblado de Pacay, a 3259 msnm, entre los UTM E0566504 y N 8595210 (WGS-84), debajo de un inmenso bloque de piedra, que cuyo interior es un abrigo natural que mide $1,90 \mathrm{~m}$ de altura y $4 \mathrm{~m}$ de profundidad, se encuentra las estructuras arquitectónicas semi destruidas, los muros de piedras y barro de $48 \mathrm{~cm}$ de ancho, de las otroras cámaras funerarias o pucullos, donde aún podemos observar los restos óseos humanos (cráneos, huesos largos, costillas y partes de la columna vertebral) que corresponden a adultos y niños, que están asociados a fragmentos de cerámica de estilo Wari y Huarpa.

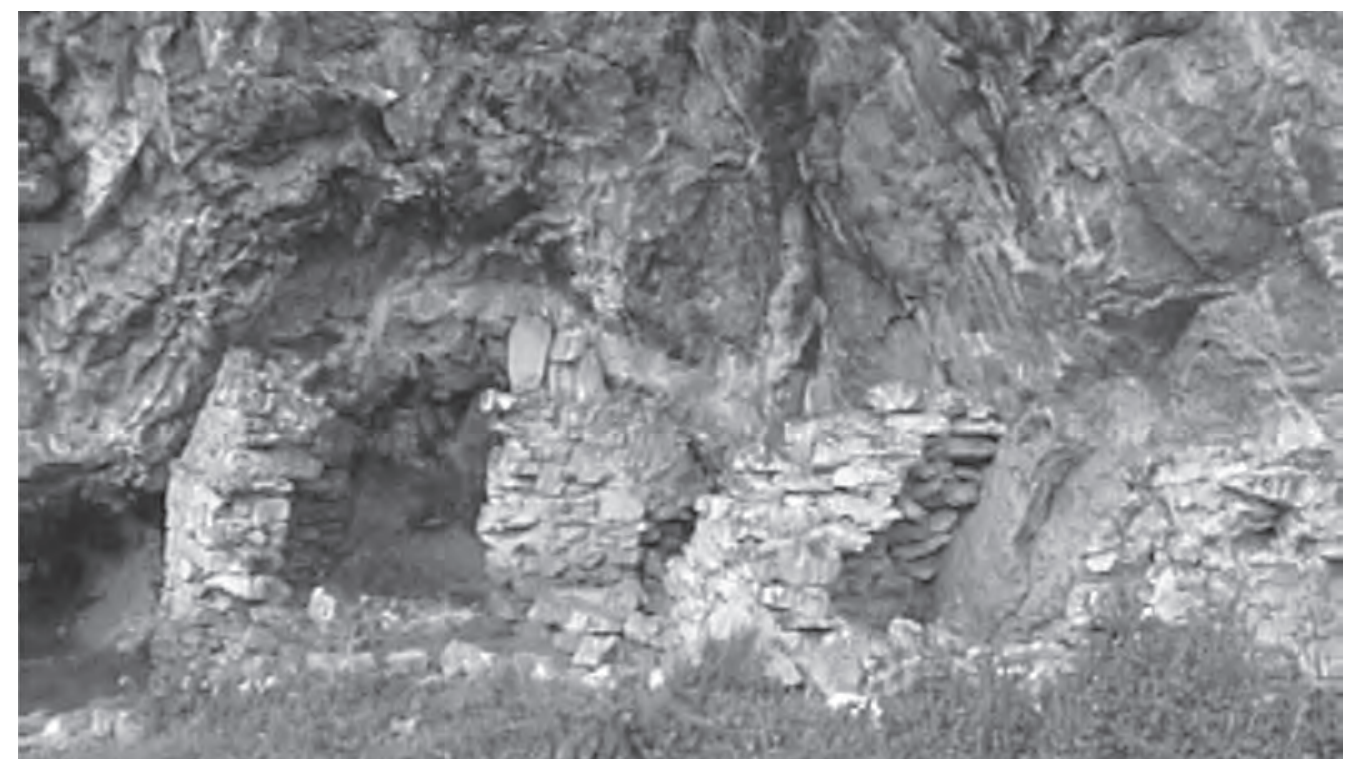

Figura 10. Véase restos de Cámaras Funerarias ubicadas en las alturas de Uchuraccay, en la comunidad de Cunya, Huanta.

V. Tenemos el sitio de Aya Samachina, que se ubica en la misma pendiente que circunda al centro poblado de Pacay, a escasos metros de la Institución Educativa de nivel secundario, debajo de la abertura o abrigo que existe en un gran bloque de piedra, a $3225 \mathrm{msnm}$ entre los UTM E0566281 y N8595608 (WGS-84), se ubican las estructuras semi destruidas de piedras y barro que corresponden a cámaras funerarias o Pucullos, que aún presenta sus cornisas y muros de $40 \mathrm{~cm}$ de ancho, que en cuyo interior aún podemos observar fragmentos de restos óseos humanos, asociado a pequeños fragmentos de cerámica del estilo Huamanga, del periodo Wari.

VI. Tenemos las cámaras funerarias o Pucullos de Arrayampata, en la misma pendiente que se desliza desde el centro poblado de Pacay hasta las profundidades del Mantaro, a $3150 \mathrm{msnm}$, entre los UTM E0566533 y N8595696 (WGS-84), debajo de un peñasco que ofrece dos espacios escalonados, en cada uno donde se presenta pequeños abrigos rocosos, están estratégicamente adaptadas las tumbas o chullpas construidas con piedras y barro.

La primera cámara adaptada al abrigo rocoso, se orienta hacia el este, y presenta cierto estuco en sus paredes, con un vano de $65 \mathrm{~cm}$ de altura, con un ancho en la base de $59 \mathrm{~cm}$, y en la pared superior de $49 \mathrm{~cm}$. El muro presenta $39 \mathrm{~cm}$ de ancho. En la parte superior hay una ventana de $51 \mathrm{~cm}$ de altura por $18 \mathrm{~cm}$ de ancho, en cuyo interior aún se aprecian algunos fragmentos de restos óseos humanos.

Debajo de este abrigo, en otra plataforma natural, aparece otra cámara funeraria aparentemente de forma circular, que presenta sus muros de $40 \mathrm{~cm}$ de ancho, construidos con piedras y argamasa, en cuyo interior aparecen evidencias de cerámica fragmentada, soguillas, sogas delgadas, telas y escasa cantidad de huesos humanos. 


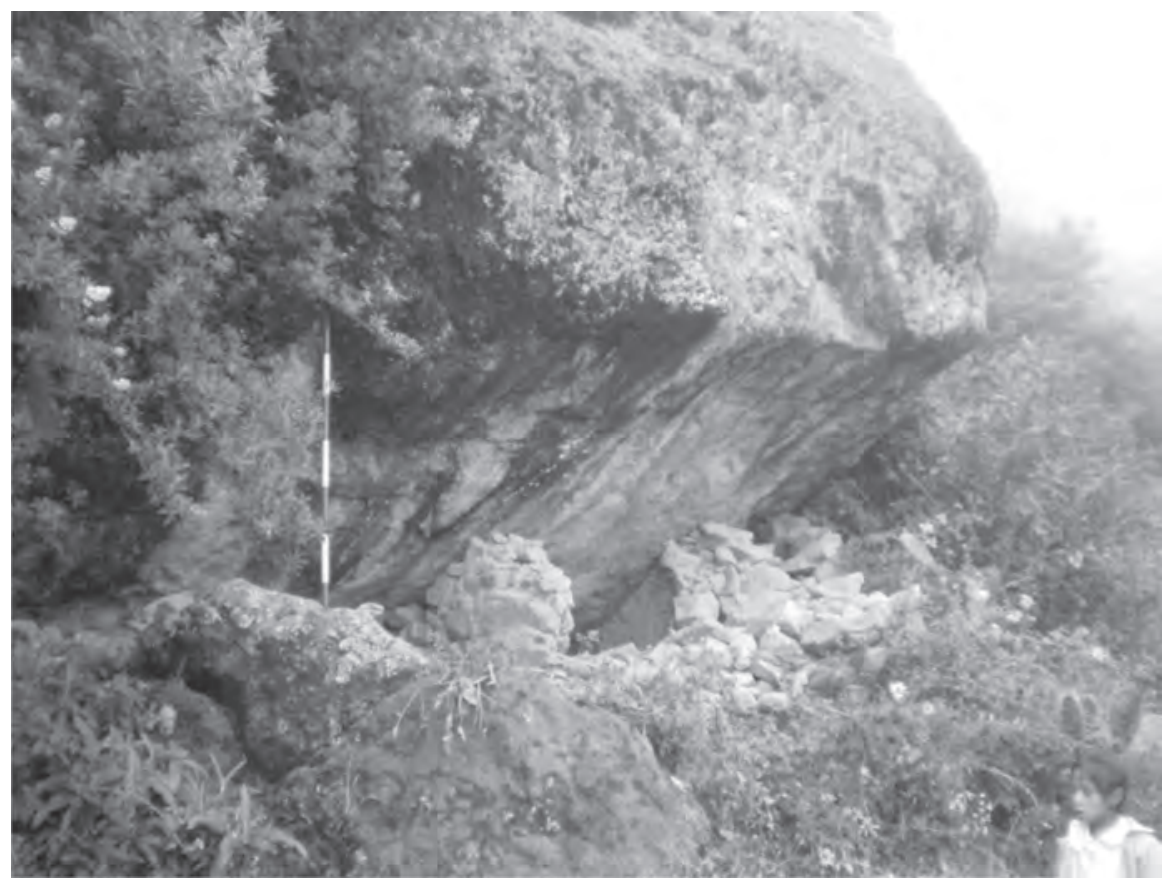

Figura 11. Véase la estructura arquitectónica destruida debajo y dentro de la cueva.

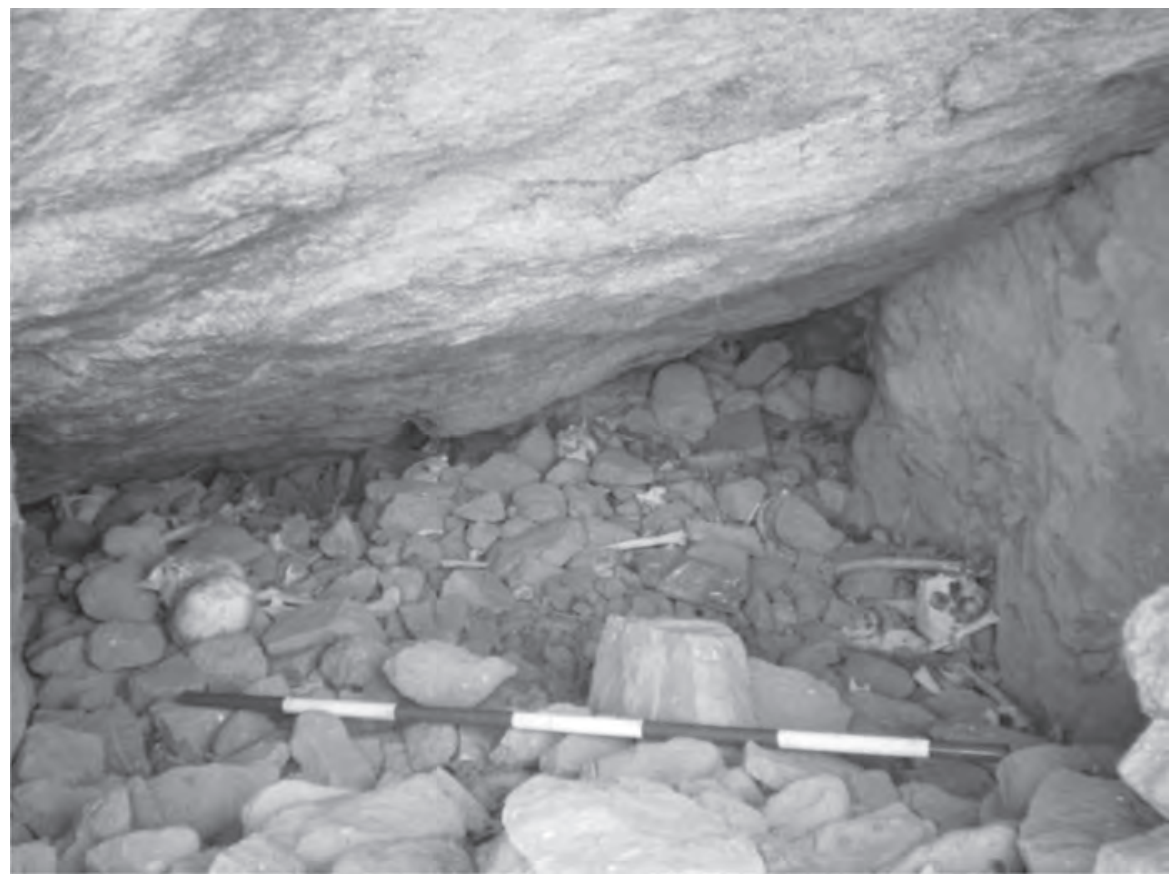

Figura 12. Véase los restos óseos dentro y debajo de la cueva. 


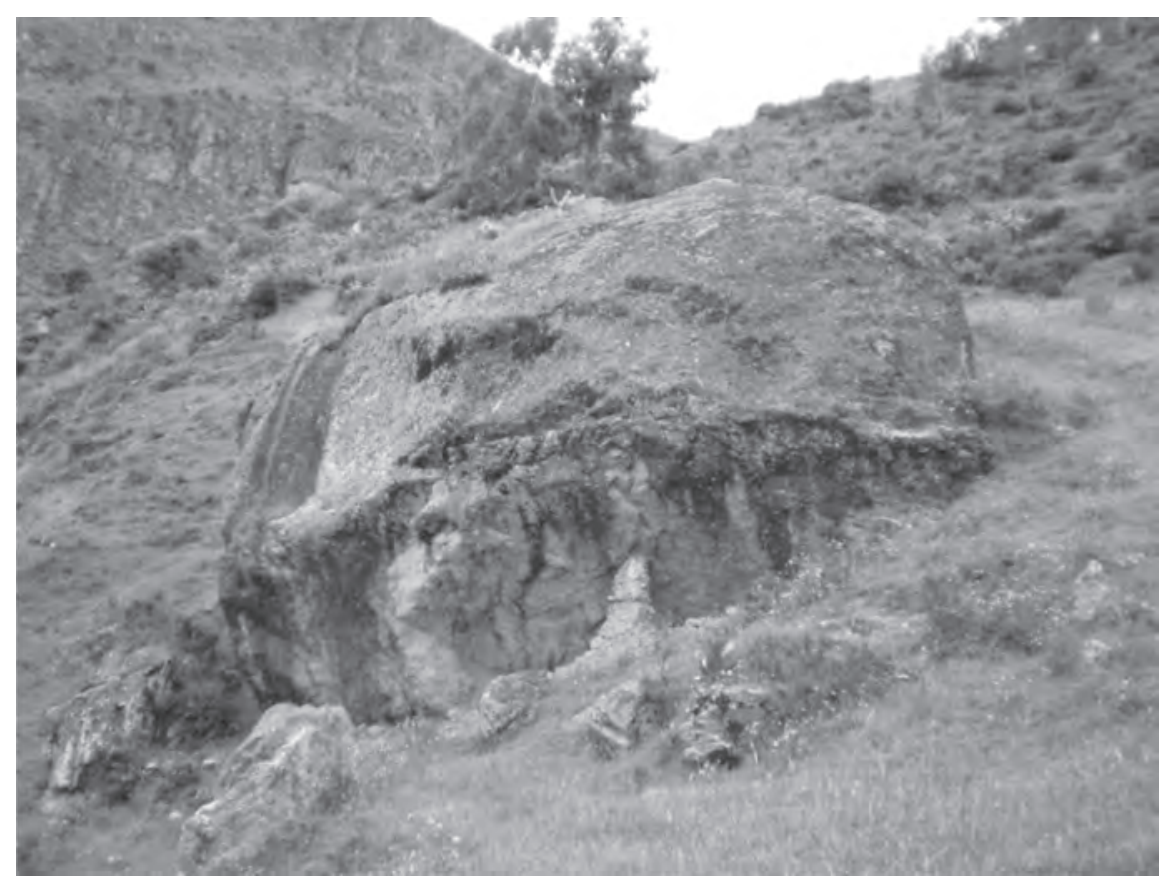

Figura 13. Véase la estructura arquitectónica destruida debajo dentro de la cueva Aya Samachina.

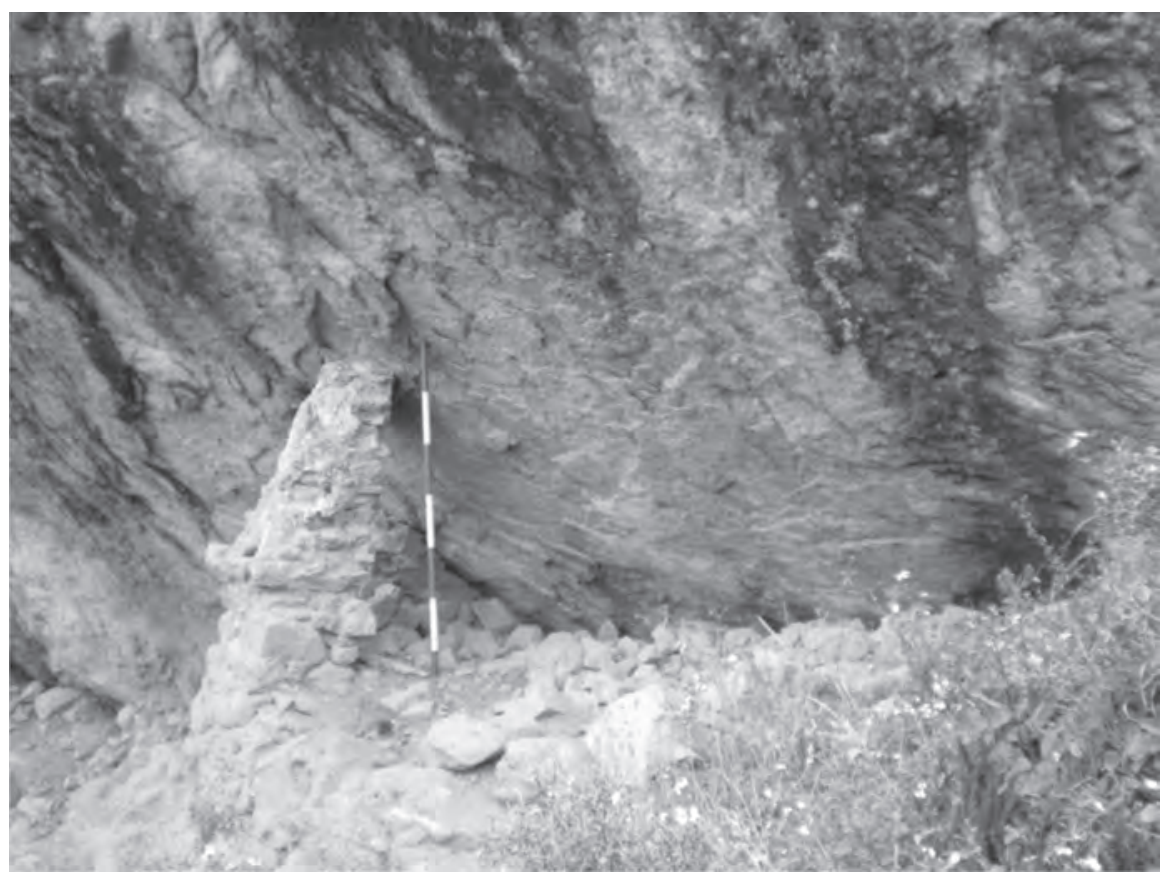

Figura 14. Véase la estructura arquitectónica destruida debajo dentro de la cueva ya Samachina. 


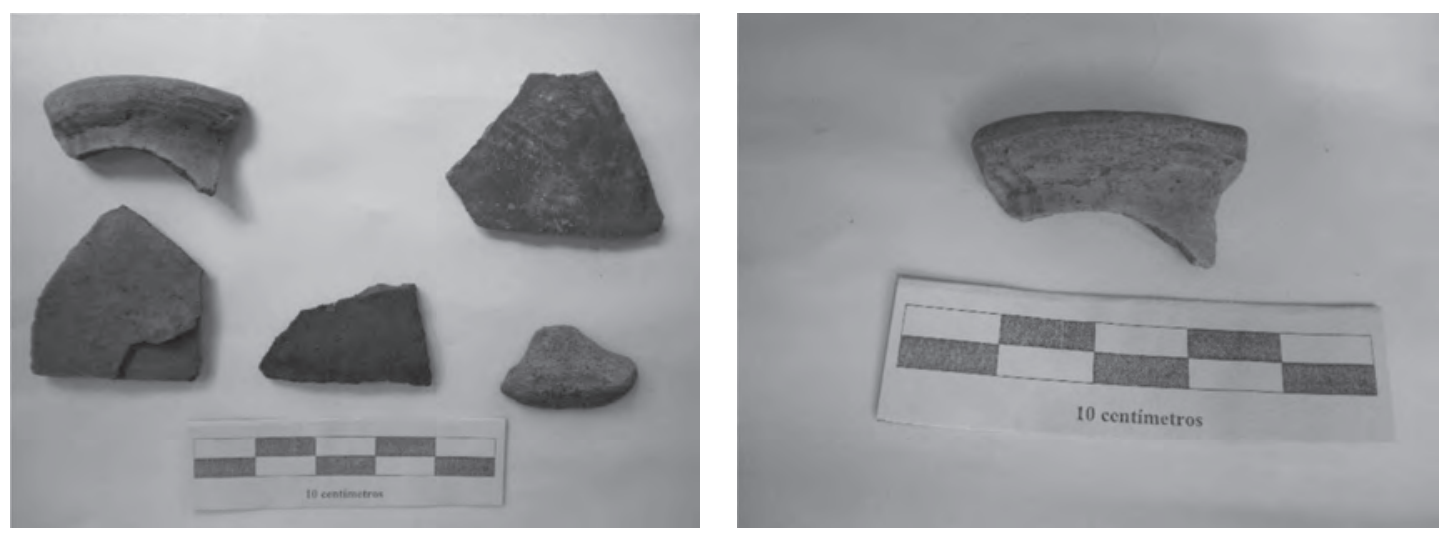

Figura 15. Véase los fragmentos de cerámica, estilo Huamanga, asociadas a la cámara funeraria de Aya Samachina.

VII. En la misma comunidad de Pacay, tenemos las cámaras funerarias de Pachamachay, sobre un terreno de fuerte inclinación, en la parte superior del centro poblado de Pacay, debajo de una piedra de grandes dimensiones, a 3250 msnm entre los UTM E 0566426 y N85955190. Se encontraron las evidencias destruidas en parte de una cámara funeraria, que presenta un vano de acceso que se orienta hacia el noreste.

VIII. En las inmediaciones de la comunidad de Ccotccoy, sobre una empinada pendiente rocosas por donde se levanta el cerro Lloqte Orqo, es frecuente observar en su entorno salidas accidentales de rocas, donde se forman algunos abrigos rocosos en zonas de difícil acceso. En una de estas pendientes, que se orienta hacia el suroeste, frente al centro poblado de Ccotccoy, a 3336 msnm entre los UTM E0565760 y N8593786, se encuentra adaptada el pucullo de Suytu Puquio, construido de piedras y barro, con pequeñas cámaras, que ofrecen pequeños espacios aptos para depositar los cuerpos de los muertos.

Actualmente este Pucullo, está relativamente destruido por el tiempo y la erosión, en su interior hay algunos fragmentos de huesos humanos, adultos y niños, que están asociados a restos óseos de cuy.

Figura 16. Véase la estructura de la cámara funeraria de Arrayampata. 


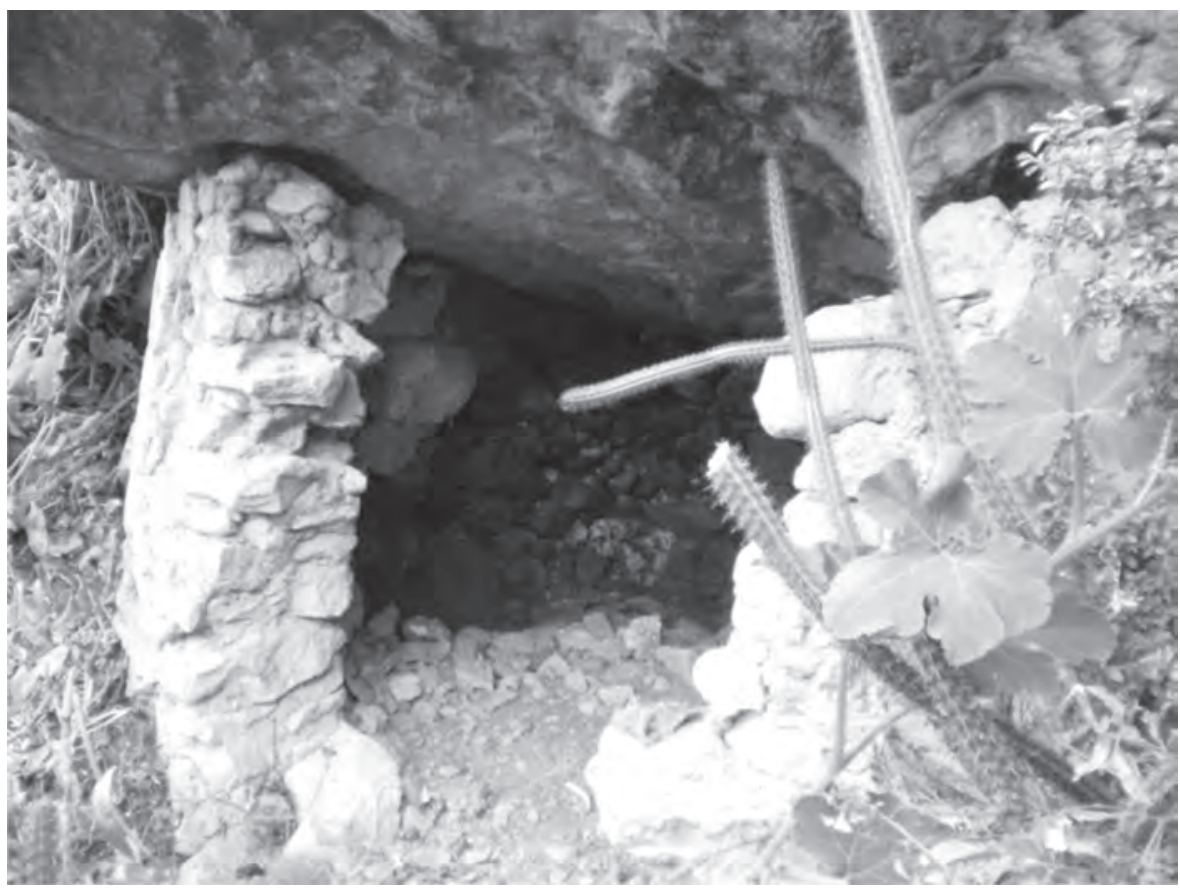

Figura 17. Véase otra estructura de cámara funeraria ubicada en otro nivel de Arrayampata.

Según Esteban Guillén Meza, natural de Ccotccoy (comunicación personal 23 de abril 2011), a poca distancia de esta tumba, debajo de una gran bloque de piedra existían dos momias unidas con soguillas de maguey, que estaban vestidas, y que hace un mes antes, como producto de las intensas lluvias de esa temporada, este bloque de piedra se desprendió y se deslizó, haciendo desaparecer a estas momias.

IX. Al noreste de la localidad de Ccotccoy, en el lugar denominado Punchau Cancha, a escasos metros de la Institución Educativa de nivel inicial de esta localidad, a $3286 \mathrm{msnm}$, entre los UTM E0586930 y N8555904, debajo de un inmenso bloque de piedra hay algunos abrigos con una boca de abertura de unos $2,10 \mathrm{~m}$, donde se ha llegado a construir muros de $45 \mathrm{~cm}$ de ancho con piedras y barro, conformando estructuras funerarias, que encierran espacios irregulares de $3 \mathrm{~m}$ de diámetro, en

Figura 18. Véase la estructura arquitectónica de la cámara funeraria reconstruidas para fines de horno, en Pachamachay.Arrayampata.

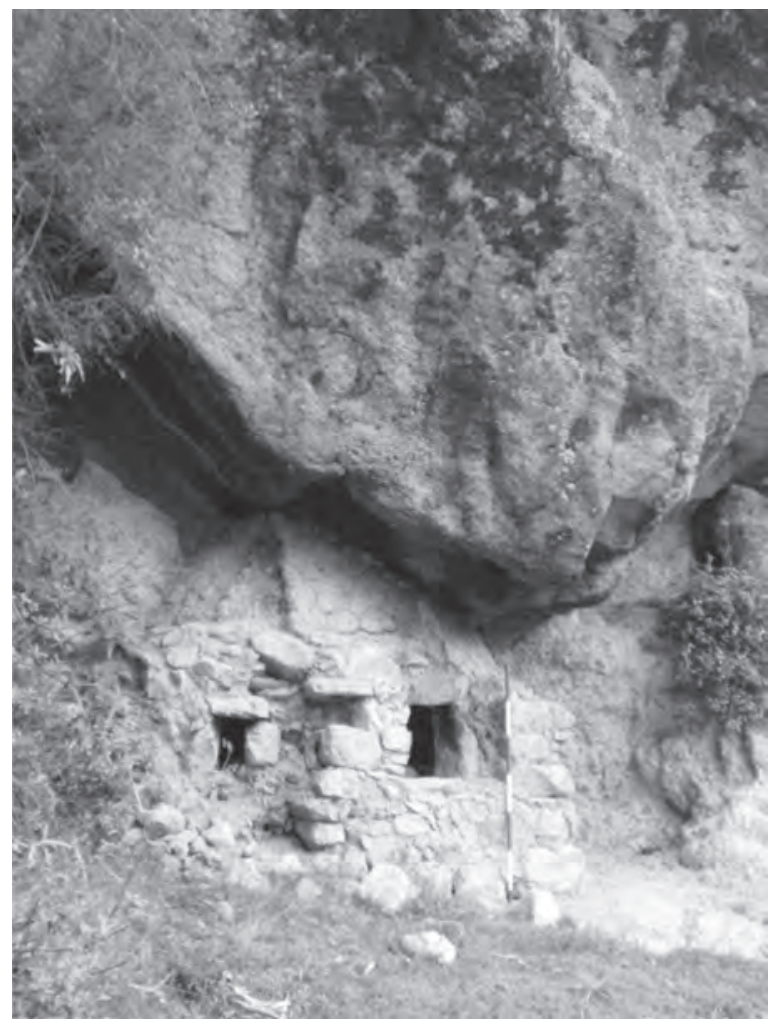


Figura 19. Véase la estructura arquitectónica de la cámara Funeraria de Suytu Puquio debajo de la cueva.

las que depositaban los muertos. Evidencia de ello, aún dentro de estas estructuras ya destruidas, podemos observar restos óseos muy fragmentados. Curiosamente para construir estas estructuras lograron utilizar ambos lados de la gran roca, donde adaptaron las chulpas.

\section{Discusión}

Los trabajos de investigación llevados a cabo en sitios arqueológicos en esta zona de la cuenca del rio Warpa, dejan claro que durante el Horizonte Medio, en lo que corresponde a prácticas funerarias, hubo variadas formas de patrones de enterramiento. Estas formas diversas de enterrar, se han logrado registrar como en el caso del sitio arqueológico de Chillikupampa (Valdez 2006); igualmente Lidio Valdez para el caso de Marayniyuq (2005), Anders para el caso de Azángaro. Esto significa que, en un solo sitio que
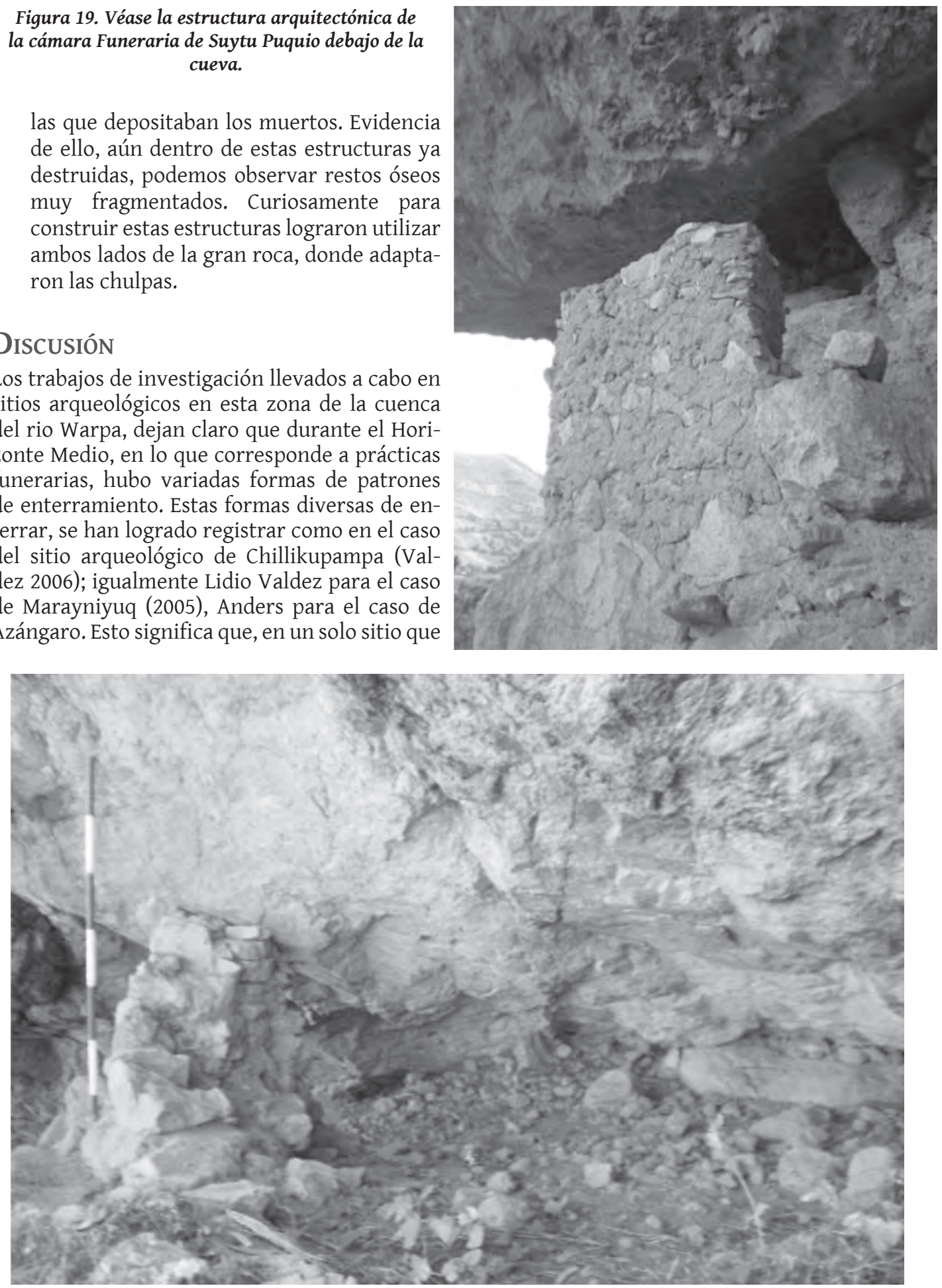

Figura 20. Véase la estructura arquitectónica destruida de la cámara funeraria de Punchau Cancha. 
corresponde a un determinado periodo, se expusieron diversos patrones de enterramiento, que a la larga nos lleva a suponer que se debió a la estructura social existente, que se resumía en la existencia de una sociedad con clases.

La presencia de las cámaras funerarias que están dentro de las cuevas y abrigos rocosos en ciertos peñascos y que no están directamente asociados a un sitio arqueológico alguno, tal como se hace conocer en este artículo, necesariamente nos invita formularnos algunas interrogantes, como ¿por qué estos construyeron sus cámaras en estos lugares? ¿Ellos fueron provenientes de asentamiento similares, como Conchopata, Chillikupampa, etc. o fueron sociedades rurales que cuyos habitantes en estos tiempos vivieron dispersos? ¿Fueron sociedades marginales durante el Horizonte Medio?

Los motivos que los llevó a construir estos Pucullos en tales lugares, habría que tratar de respondernos primero entendiendo que significaba el Machay en la cosmovisión andina. La presencia de una cueva - llamada Machay- en tiempos incaicos, eran temidas y en ellas se guardaban a los muertos - ofreciéndoles coca y maíz mascado-y dentro de una tumba. Esto concuerda con la concepción ideológica que se gestó en las culturas andinas, y que llegó a su máxima expresión durante la sociedad Incaica. En esta, el universo se divide en tres espacios que a la vez son complementarios: El Hanan Pacha, Kay Pacha y Uku Pacha. Estos espacios están intercomunicados por muchos canales. Veamos sólo en el caso de la intercomunicación del mundo de Kay Pacha y el Uku Pacha. En el Kay Pacha, que es el mundo en el que vivimos, se expresa el Uku Pacha o se comunica por las llamados Pacarinas. Estos mundos no están incomunicados entre sí. Entre el mundo de adentro y el mundo de aquí hay un comunicación a través de las oquedades de la superficie de la tierra, que son las cavernas o cuevas; los cráteres volcánicos; lo son también por lo profundo de las lagunas o los lugares por donde brota el agua, fuentes y manantiales. Todos estos puntos de contacto o canales de comunicación con el mundo de adentro son lo que los antiguos peruanos llamaron pacarinas, palabra que viene del verbo "pacary» que significa tanto surgir como amanecer; tal como aparece la luz en la aurora. Se relaciona esta creencia estrechamente con el mito, según el cual los primeros hombres de cada linaje salen del interior o sea del «Uku pacha» y por estos caminos (cuevas, fuentes, cráteres, etc.) surgen a la vida de aquí (Valcárcel. 1980:79-80). En conclusión, hay una continua relación entre los tres mundos.

El entierro dentro de la cueva en esta concepción andina tiene su razón de ser: «Así como la semilla debe ponerse bajo la tierra para que surja las plantas, del mismo modo hay que enterrar a los muertos para que vuelvan a nacer hombres. Entre el cadáver y el germen hay una relación estrecha que se hace más patente cuando se examina la palabra mallqui, que significa por igual en quechua: almácigo y momia. Muertos y gérmenes quedan en una ecuación en que el término común es mallqui.» (Ibid: 81-82). Dentro de esta acción y viceversa entre el mundo de aquí y el mundo de abajo, enterrar a los muertos aquí en cuevas (pacarinas) fue como sí enviaran un mensajero al mundo de adentro. El muerto lleva el mensaje dentro de su ajuar funerario y ahí tenemos la cerámica, los tejidos cubiertos en su gran mayoría por símbolos mágicoreligiosos. La influencia del mundo de adentro en el mundo de aquí es directa, sobre todo en lo que se relaciona con la fecundidad, porque si no brotan las semillas y de ellas la planta, quiere decir que el mundo de abajo no lo ha permitido. Por eso hay que tener favorablemente inclinados a los habitantes del mundo subterráneo; de esta idea proviene el culto a los muertos». (Ibid: 82-83).

De ser esta una continuidad en la cultura andina, entonces, enterrar a los muertos dentro de abrigos rocosos o cuevas, respondería no solo por el afán de preservar el cuerpo del antepasado, sino más aún, existe la necesidad de enviar al muerto, con sus ofrendas y todo, al lugar de donde surgió, hacia el Ukupacha. Evidencia de patrones de enterramiento como las de esta zona, no es solo atribuible al Horizonte Medio, sino que existen enterramientos similares atribuibles a la cultura Chanka (Gonzales 1992), como también durante el periodo Inka fue una práctica común (Valdez 2002). Es más, toda esta tradición de enterrarse en las cuevas es una continuidad para esta zona de Ayacucho. A razón de ello se ha llegado a construir muchos mitos sobre los restos humanos hallados en las cuevas en posición de cuclillas, tal como lo menciona Tom Zuidema: 
«En los pueblos del Departamento de Ayacucho- y probablemente también en otras partes del Perú- hay una tradición sobre los numerosos huesos humanos y fragmentos de cerámica prehispánica que se encuentra en cuevas, a menudo cerca de las ruinas de pueblos antiguos. Se dice que estos huesos y fragmentos pertenecían a los "gentiles», los paganos, hombres muy inteligentes que habian hecho obras de irrigación y terrazas, multiplicándose notablemente. A pesar de eso, eran malos. Cometieron incesto, se comieron a sus hijos e hicieron muchas guerras. Por estas razones había que destruirlos, pero muchos intentos fallaron. Sin embargo, hubo una vez en que dos soles aparecieron en el cielo (en otra versión son tres), y ni siquiera ellos pudieron resistir tanto calor en sus cuevas y así es como todos murieron y rompieron sus ollas» (Zuidema 1989: 202).

La presencia de ofrendas, es parte de este ritual. Se cree que el individuo, en el más allá, después de la muerte, va necesitar muchos objetos que en vida ha utilizado. Así vamos a encontrar como ofrendas, sus propios utensilios que en vida fueron de su uso. Tenemos por ejemplo parte del Mate, Cerámica, palos de Chonta, etc. En lo respecta al Mate, tanto en Ayamachay, como en Gentilpata, se ha reportado la presencia de fragmentos de Mate con evidencias de haber sido burilado. Consideramos que al igual que la cerámica, el mate cumplió un papel importante dentro de la vida doméstica del poblador andino, cumpliendo la función de un recipiente, muchas veces para guardar elementos líquidos o como un plato para ingerir los alimentos. Para el poblador de esta zona, fue fácil tener acceso a este elemento, debido a que en las hondonadas por donde pasa el Hantunmayu o río Mantaro, por una zona cálida donde se ubica la localidad de Mayoc, aún existe la costumbre de sembrar el mate hasta tiempos recientes; tal como nos cuenta el Sargento Mayor Francisco José Cañas, funcionario y viajero empedernido de la primera mitad del siglo XIX: «el clima ardiente de esta zona les permitía la obtención de una gran cantidad de calabazas o mates, cuyos caparazones eran burilados en Mayoc con extraordinario gusto artístico» (Espinoza 1973: 9).

En el caso de la Chonta, elemento que fue encontrado en Gentilpata, es una palmera cuyo tallo es un material muy resistente y duro, "parecido a un metal». En la cultura andina, este material fue utilizado como asada para remover la tierra, como punzón para sembrar la semilla en el suelo, como vara que es un bastón de mando, como palo para hilar llamado el «Puchca tullo». Esta planta es natural de zonas cálidas y tropicales, y su única forma de abastecer a estas zonas de los valles interandinos como es el caso del valle de Huanta, solo fue posible desde el valle del río Apurímac, donde naturalmente abunda. Esto demuestra que entre el valle del río Warpa y el valle del río Apurímac hubo una antigua interconexión, tal vez bajo las modalidades de control vertical de los pisos ecológicos tal como propone John Murra (1975) para otras zonas del área andina.

¿Quiénes fueron estas personas que construyeron este tipo de tumbas en peñascos y abrigos rocosos? Si tomamos como ejemplo al estado Inka, dentro de este poder político existían muchas naciones, grupos que tenían sus propias costumbres, su propio idioma y su propia historia necesariamente. Y desde luego los inkas respetaron estas costumbres. ¿Porque no pensar que algo similar paso durante el Horizonte Medio?. Seguramente la hegemonía Wari, durante el Horizonte Medio, controló varias nacionalidades. Estas no necesariamente habitaron en asentamientos conglomerados en un solo lugar, sino que cada ayllus vivieron desperdigados en diferentes lugares de una cuenca, por ejemplo, pero sin perder su vínculo ancestral que los unía mediante algunos sistemas como el ayni, la minka, etc. Entonces estas sociedades «rurales» con tradiciones diferentes, desde luego tuvieron formas diferentes de enterrarse, y sus tumbas fueron estas cámaras ubicadas debajo de riscos, y que en sociedades posteriores, como durante los Chankas y los inkas aun continuaron practicando. En ese sentido, pudiera especularse que cada sitio era para un ayllu, motivo por la que cada ayllu enterraba a sus miembros en sus respectivos sitios, y cada ayllu cuidaba las áreas funerarias. Porque si hacemos una observación detenida de las estructuras funerarias, estas están hechas con cierta maestría, lo que implica que se ha dedicado en su construcción mucho trabajo. Pero solo futuras investigaciones más exhaustivas podrán aclarar estas especulaciones. 
En la historia prehispánica de esta zona, se ha registrado evidencias de cómo las gentes enterraban a sus muertos. Y particularmente para el caso del Horizonte Medio, durante la hegemonía Wari, en estas zonas del Ande, igualmente se viene recogiendo datos de las formas de enterramiento de los muertos, que fue producto de cómo la sociedad respondió ante este fenómeno. Es posible que el tratamiento de los muertos, tal como dice Jean-Pierre Chaumeil (1997) para otras sociedades, no fue uniforme para todo los muertos en una cultura dada, variando mucho su destino en función de edad, sexo, status social, lugar del deceso y las formas de vivir; como también a su ubicación geográfica, ubicación temporal y las circunstancias de su muerte.

\title{
CONCLUSIONES
}

1. Existe información de que en toda esta configuración geográfica donde se ubica la cuenca del río Warpa, el río Urubamba y en todo el cañón creado por el río Mantaro, existen estructuras funerarias características y de forma similar, debajo de grandes peñascos en abrigos rocosos.

2. Estas estructuras funerarias están dotadas de un acceso. Dicho acceso implicaba evidentemente que la estructura funeraria podía ser abierta y reabierta en más de una oportunidad, lo que significa que fue utilizada para varias generaciones, y posiblemente cada abrigo fue para un ayllu. Entonces quedaba claro que nuevos cuerpos podían ser introducidos al interior de la estructura en diversas épocas, motivo por lo que existe la presencia de numerosos restos humanos, de diferentes sexos y edades al interior de estas estructuras.

3. Las informaciones orales recogidas nos detallan que los cuerpos estaban en posición sentada, estaban enfardelados, a lo que en quechua se llama Ayahuancos, (muertos cubiertos con tela). Razón por lo que es frecuente observar la presencia de fragmentos de soguillas y telas asociadas a los restos óseos en estas tumbas, como evidencia de que estaban cubiertos y enfardelados.

4. Los cuerpos estaban acompañados de ofrendas, y muchos de estas eran posiblemente objetos perecibles, de las que solo se ha recuperado evidencias de fragmentos de cerámica de recipientes y mates. Según cuenta Guanan Poma de Ayala, «Creían que en la otra vida los muertos pasaban trabajos, tormentos, hambre, sed, frí y calor, demostrando con esto conocer la existencia del infierno, al que llamaban Ucupacha Supaypa Uacin, mundo debajo de la tierra o casa del demonio; por esta razón enterraban junto con sus muertos, alimentos, bebidas, vestidos, utensilios de plata y muchas veces también enterraban con ellos a la mujer a fin de que fueran servidos por esta en el otro mundo. Además lloraban por sus muertos por que sabían los padecimientos que estos iban a sufrir» (Bustios 1956:51).

5. Durante el Periodo del Horizonte Medio, en estas zonas de la cuenca del valle del río Warpa, se ha logrado identificar la práctica de diversos patrones de enterramiento, que seguramente respondían a factores como el nivel que ocupaban en la estructura social, origen, etc.

\section{BiBLIOGRAFÍA}

\author{
ARROYO, Sabino \\ 2008 Culto a los Hermanos Cristo. Sistema Religioso Andino y cristiano: Redes y formas culturales del Poder en los \\ andes. Lima: UNMSM. \\ ARROYO, Abilio \\ 1996 CHURCAMPA. Península del Mantaro. Región Libertadores Wari. Municipalidad de Churcampa. \\ BARTOLEMÉ DE LAS CASAS \\ 1892 De las antiguas gentes del Perú. Colección de libros españoles raros o curiosos. Madrid. \\ BUSTIOS, Luis \\ 1956 El Primer nueva coronica i buen gobierno por don Phelipe Guaman Poma de Ayala. Lima. \\ CHAUMEIL, Jean-Pierre \\ 1997 «Entre la Memoria y el Olvido. Observaciones sobre los ritos funerarios en las tierras bajas de \\ América del Sur». Boletín de Arqueologia PUCP 1: 207-232.
}


ESPINOZA SORIANO, Valdemar

1973 La destrucción del Imperio de los Incas: la rivalidad política y señorial de los curacazgos andinos. Instituto nacional de investigación y desarrollo de la educación. INIDE, Subdirección de publicaciones y material educativo - Retablo de papel. Lima.

GONZALES CARRE, Enrique

1992 Historia prehispánica de Ayacucho. UNSCH.2DA EDICIÓN.

1992 Los Señorios Chankas. Universidad Nacional de San Cristóbal de Huamanga e Instituto Andino de Estudios Arqueológicos.

ISBELL, William $\mathrm{H}$.

2000 «Repensando el Horizonte Medio: El Caso de Conchopata, Ayacucho, Perú». Boletín de Arqueología PUCP. 4: 9-68.

LUMBRERAS, Luis G.

1974 Las Fundaciones de Huamanga: hacia una Prehistoria de Ayacucho. Lima: Club de Huamanga editores.

MURRA, John V.

1975 Formaciones Económicas y políticas del mundo andino. Lima: IEP.

OCHATOMA PARAVICINO, José

1998 «El Periodo Formativo en Ayacucho: Balances y Perspectivas». Boletín de Arqueología PUCP 2: 289302. Perspectivas Regionales del Periodo Formativo en el Perú. Lima: PUCP.

PULGA Vidal

1976 Geografía del Perú: Ocho Regiones Naturales del Perú. Lima: Ed. Universo.

RAVINES Rogger

2008 «Las chullpas de Sillustani. Encuentros y desencuentros». Boletin de Lima XXX(151): 45-72.

ROFES, Juan

2000 «Sacrificio de cuyes en el Yaral, comunidad prehispánica del extremo sur peruano». Bulletin de l'Institut français d'études andines, 29(1): 1-12. Lima.

VALCÁRCEL. Luis E.

1980 «La religión incaica». Historia del Perú. Tomo III: 75-202. Lima: Ed. Mejía Baca.

VALDEZ, Julio Ernesto

2003 «Pueblos del Periodo Intermedio Tardío». Revista Arqueológica Warpa 3: 3-27. Huanta.

2006 «Patrones de enterramiento prehispánico en Pusuquypata-Huanta». Revista Arqueológica Warpa 12: 3-27. Huanta.

VALDEZ Lidio, K. BETTCHER y VALDEZ Ernesto

2000 «Una Cámara funeraria en Seqllas, valle de Ayacucho». Boletín del Museo de Arqueología y Antropología 3 (7): 2-7. Lima: UNMSM.

VALDEZ Lidio

2002 «Y la tradición continua: La alfarería de la época Inka en el Valle de Ayacucho, Perú». Boletin d Arqueologia PUCP 6: 395-410.

VALDEZ Lidio, VALDEZ Ernesto y Katrina BETTCHER

2005 «Prácticas funerarias Wari del valle de Ayacucho, Perú». En: Corrientes Arqueológicas: Muerte y evidencias funerarias en los andes centrales: avances y perspectivas 1: 173-198.

WEISS, Pedro

1962 «Tipología de las deformaciones cefálicas de los antiguos peruanos, según la osteología cultural» Revista del Museo Nacional 31: 15-42. Lima.

ZUIDEMA Tom

1989 Reyes y guerreros. Ensayo de Cultura Andina. Lima: Fonciencias. 